\title{
CAM use among overweight and obese persons with radiographic knee osteoarthritis
}

\author{
Kate L Lapane ${ }^{1 *}$, Shibing Yang ${ }^{2}$, Rachel Jawahar ${ }^{2}$, Timothy McAlindon ${ }^{3}$ and Charles B Eaton ${ }^{4,5}$
}

\begin{abstract}
Background: Obesity is associated with knee pain and is an independent predictor of incident knee osteoarthritis $(\mathrm{OA})$; increased pain with movement often leads patients to adopt sedentary lifestyles to avoid pain. Detailed descriptions of pain management strategies by body mass index (BMI) level among OA patients are lacking. The objectives were to describe complementary and alternative medicine (CAM) and conventional medication use by BMI level and identify correlates of CAM use by BMI level.

Methods: Using Osteoarthritis Initiative baseline data, 2,675 patients with radiographic tibiofemoral OA in at least one knee were identified. Use of CAM therapies and conventional medications was determined by interviewers. Potential correlates included SF-12, CES-D, Western Ontario and McMaster Universities Osteoarthritis Index, and Knee injury and Osteoarthritis Outcome Score quality of life. Multinomial logistic regression models adjusting for sociodemographic and clinical factors provided estimates of the association between BMI levels and treatment use; binary logistic regression identified correlates of CAM use.

Results: BMI was inversely associated with CAM use (45\% users had BMl $\geq 35 \mathrm{~kg} / \mathrm{m}^{2} ; 54 \%$ had BMl $<25 \mathrm{~kg} / \mathrm{m}^{2}$ ), but positively associated with conventional medication use ( $54 \%$ users had BMI $\geq 35 \mathrm{~kg} / \mathrm{m}^{2} ; 35.1 \%$ had BMl $<25 \mathrm{~kg} / \mathrm{m}^{2}$ ). Those with $\mathrm{BMI} \geq 30 \mathrm{~kg} / \mathrm{m}^{2}$ were less likely to use CAM alone or in combination with conventional medications when compared to patients with $\mathrm{BMl}<25 \mathrm{~kg} / \mathrm{m}^{2}$.
\end{abstract}

Conclusions: CAM use is common among people with knee OA but is inversely associated with BMI. Understanding ways to further symptom management in OA among overweight and obese patients is warranted.

Keywords: Knee osteoarthritis, Obesity, Pain, Complementary and alternative medicine

\section{Background}

Obesity is an independent predictor of incident knee osteoarthritis (OA) [1]. Both weight gain and malalignment are also associated with increased pain and functional loss [2]. OA patients with body mass index (BMI) $\geq 35 \mathrm{~kg} / \mathrm{m}^{2}$ often experience increased pain due to significant increases in joint stress and load forces on the knees [3]. Obesity is a modifiable risk factor for the development and treatment of knee pain [4]. In two major trials [5,6], people randomized to intensive lifestyle interventions which focused on exercise and weight loss demonstrated improvements in pain and physical function relative to controls. Interventions including both exercise and weight loss were more successful than those using either approach alone [7].

\footnotetext{
* Correspondence: kate.lapane@umassmed.edu

${ }^{1}$ Department of Quantitative Health Sciences, University of Massachusetts Medical School, Worcester, MA, USA

Full list of author information is available at the end of the article
}

Diffusing interventions is challenging because increased pain with movement often leads patients to adopt sedentary lifestyles to avoid pain, which leads to more weight gain, pain, and disability.

$\mathrm{OA}$ is a chronic disease with no cure so patients often treat pain with conventional medications or therapies [8] and complementary and alternative medicines (CAM) $[9,10]$. Glucosamine [11] and acupuncture [12] do relieve symptoms among OA patients. Obese adults are less likely to use CAM overall [13], but detailed CAM practices among people with higher BMI are unknown.

The Osteoarthritis Initiative (OAI) provides the opportunity to address this gap in the literature. The OAI is a multi-center, prospective observational study which examines the natural history of and identifies risk factors for incidence and progression of knee OA [14]. The OAI is a unique data source because it provides a population 
with radiographic confirmation of $\mathrm{OA}$ and detailed assessments of knee-specific pain, quality of life, and functioning indicators using standardized instruments. The study purpose was twofold: 1) to describe differences in treatment approaches to manage symptoms of knee OA by level of BMI; and 2) to evaluate the extent to which sociodemographic and clinical correlates of CAM use differed by BMI.

\section{Methods}

The University of Massachusetts Medical School Institutional Review Board reviewed and approved the protocol for this study. Because publicly-available data were used for this study, the Institutional Review Board waived the need for documentation of informed consent from participants.

We used publicly available data from the OAI (http:// www.oai.ucsf.edu/) (\#AllClinical00, V0.2.2). The OAI began recruiting in 2004 and engaged 4,796 participants aged 45 to 79 years. At baseline, each participant underwent 3.0 Tesla MRI examinations of the knee and provided blood samples, and each clinical site had readers (trained through didactic and interactive webbased methods) assess fixed flexion knee x-rays for osteophytes and joint space narrowing. Eligibility was restricted to those without severe joint space narrowing in both knees. The participants were followed annually for the development or progression of knee OA. We included 2,679 individuals with radiographic tibiofemoral knee OA (e.g. OARSI atlas osteophyte grade I-III) [15] in at least one knee at baseline and excluded 4 participants with missing height and/or weight measured using standardized methods $(n=2,675)$. Participants were classified into four categories: BMI less than $25 \mathrm{~kg} / \mathrm{m}^{2}$, BMI between 25 and less than $30 \mathrm{~kg} / \mathrm{m}^{2}$ (overweight), BMI from 30 to less than $35 \mathrm{~kg} / \mathrm{m}^{2}$ (obese), and BMI of at least $35 \mathrm{~kg} / \mathrm{m}^{2}$ (severe obesity) [16].

\section{Classification of use of CAM and conventional medications}

Complementary and alternative therapies were defined as [9]: 1) alternative medical systems (e.g. homeopathy, acupuncture); 2) mind-body interventions (e.g. pilates, spiritual activities, relaxation therapy); 3) manipulation

Table 1 Sociodemographic and descriptive characteristics of participants with radiographic-confirmed knee OA by BMI level $(\mathrm{N}=\mathbf{2 , 6 7 5})$

\begin{tabular}{|c|c|c|c|c|}
\hline & $\begin{array}{c}B M I \geq 35 \mathrm{~kg} / \mathrm{m}^{2} \\
(\mathrm{n}=364)\end{array}$ & $\begin{array}{l}\text { BMI between } 30 \text { and }<35 \mathrm{~kg} / \mathrm{m}^{2} \\
\qquad(\mathrm{n}=804)\end{array}$ & $\begin{array}{l}\text { BMI between } 25 \text { and }<30 \mathrm{~kg} / \mathrm{m}^{2} \\
\qquad(\mathrm{n}=1,042)\end{array}$ & $\begin{array}{c}\text { BMI }<25 \mathrm{~kg} / \mathrm{m}^{2} \\
\quad(\mathrm{n}=465)\end{array}$ \\
\hline & \multicolumn{4}{|c|}{ Percentage } \\
\hline Age (years): $\geq 65$ & 27.5 & 39.6 & 48.9 & 49.9 \\
\hline Women & 69.0 & 57.8 & 50.3 & 69.0 \\
\hline Race/ethnicity: White & 58.8 & 72.7 & 82.7 & 89.3 \\
\hline African American & 38.7 & 24.3 & 13.3 & 6.5 \\
\hline Latino & 1.1 & 0.8 & 1.8 & 1.7 \\
\hline Other & 1.4 & 2.2 & 2.1 & 2.6 \\
\hline Education: $\geq$ College graduate & 40.8 & 50.4 & 59.9 & 66.2 \\
\hline Some college & 36.9 & 28.2 & 22.7 & 21.3 \\
\hline$\leq$ High school & 22.4 & 21.3 & 17.5 & 12.6 \\
\hline Income $(\$):>100,000$ & 15.6 & 20.1 & 24.3 & 22.4 \\
\hline $50 \mathrm{k}-100 \mathrm{k}$ & 29.9 & 35.8 & 36.2 & 40.0 \\
\hline $25 k-50 k$ & 31.4 & 27.9 & 26.7 & 24.0 \\
\hline$\leq 25,000$ & 23.1 & 16.2 & 12.8 & 13.7 \\
\hline Married/partnered & 53.4 & 62.9 & 68.8 & 73.9 \\
\hline Working (for pay) & 65.1 & 61.1 & 57.0 & 52.3 \\
\hline Health insurance & 91.6 & 96.1 & 98.3 & 98.5 \\
\hline Insurance covers prescriptions & 83.3 & 87.5 & 87.9 & 86.7 \\
\hline \multirow[t]{2}{*}{ CES-D > 16 (Depressed) } & 15.9 & 10.1 & 7.2 & 7.5 \\
\hline & \multicolumn{4}{|c|}{ Mean (standard deviation) } \\
\hline Weight at age $25(\mathrm{~kg})$ & $71.7(14.9)$ & $70.8(14.7)$ & $67.7(13.1)$ & $60.7(10.1)$ \\
\hline SF-12* Mental summary & $52.3(9.5)$ & $53.4(8.6)$ & $54.7(7.5)$ & $53.9(7.9)$ \\
\hline SF-12* Physical summary & $42.4(10.6)$ & $46.8(9.3)$ & $48.6(9.0)$ & $50.9(8.0)$ \\
\hline
\end{tabular}

*SF-12 (range: 0 to 100 with higher scores indicating better health). 
and body-based methods (e.g. massage and chiropractic); 4) energy therapies (e.g. copper bracelets); 5) topical biologically based therapies including rubs (e.g. tiger balm); 6) biologically based diet; or 7) biologically based supplements (e.g. glucosamine, chondroitin). CAM use for the past year was determined by a series of questions including, "During the past 6 months, did you use the following health supplements for joint pain or arthritis?" Conventional medication use was captured in baseline surveys as self-reported use. A four-level outcome variable was created: CAM use only, conventional medication use only, both, and no use.

\section{Potential correlates}

Treatment of OA is influenced by sociodemographic indicators, overall measures of mental and physical wellbeing, and clinical indices of OA. We anticipated CAM use to be different by age group [17], gender [18], race/ ethnicity [19,20], education [21], annual household income, employment status, and health insurance status. Physical and mental health status were assessed by the 12-item Medical Outcomes Study Short Form (SF-12) [22] (range from 0 to 100, with higher scores indicating better health status). Depression status was measured with the CES-D Scale $(\geq 16)$ [23].
A pain score of 20 in the Western Ontario and McMaster Universities (WOMAC) Osteoarthritis Index (Version LK 3.1) [24,25] indicated the worst pain (range 0 to 20). Knee-related quality of life was measured by the Knee injury and Osteoarthritis Outcome Score (KOOS) by calculating a summary score ranging from 0 to 100 (range: 0 (extreme symptoms) to 100 (no symptoms)) [26]. The knee with worse measures was used in the analysis. Walking ability and endurance were measured by a 20-meter walk, averaged over two trials [27]. The chair stand test directly assessed leg strength and knee function and duration of time (seconds) needed to stand up and sit down five times as quickly as possible [28].

Participants were classified by $x$-ray joint space narrowing as determined by OARSI atlas grade on a fixed flexion radiograph of the knee with the worst measure. Multiple-joint OA symptoms were measured with selfreported information at baseline: low back pain in previous 30 days, OA in hand, hip symptoms, and hip replacement. Information on previous history of knee injury or surgery was also collected.

\section{Analytic approach}

A multivariable multinomial logistic regression model was developed to estimate the association between BMI level and CAM/conventional treatment use after adjusting

Table 2 Clinical characteristics of participants with radiographic-confirmed knee OA by BMI level $(N=2,675)$

\begin{tabular}{|c|c|c|c|c|}
\hline & $\begin{array}{c}\mathrm{BMI} \geq 35 \mathrm{~kg} / \mathrm{m}^{2} \\
(\mathrm{n}=364)\end{array}$ & $\begin{array}{l}\text { BMI between } 30 \\
\text { and }<35 \mathrm{~kg} / \mathrm{m}^{2} \\
(\mathrm{n}=804)\end{array}$ & $\begin{array}{l}\text { BMI between } 25 \\
\text { and }<30 \mathrm{~kg} / \mathrm{m}^{2} \\
(\mathrm{n}=1,042)\end{array}$ & $\begin{array}{c}\mathrm{BMI}<25 \mathrm{~kg} / \mathrm{m}^{2} \\
(\mathrm{n}=465)\end{array}$ \\
\hline Symptoms & \multicolumn{4}{|c|}{ Mean (standard deviation) } \\
\hline WOMAC*-Pain & $6.1(4.7)$ & $4.4(4.0)$ & $3.7(3.6)$ & $2.8(3.3)$ \\
\hline $\mathrm{KOOS}^{*}-\mathrm{QOL}$ & $53.5(25.1)$ & $60.3(22.5)$ & $64.2(22.5)$ & $69.5(21.0)$ \\
\hline \multicolumn{5}{|l|}{ Function and performance } \\
\hline Isometric strength/chair stands (seconds) & $13.1(4.4)$ & $12.1(4.0)$ & $11.6(3.8)$ & $10.6(3.0)$ \\
\hline 20-meter walk (seconds) & $17.5(4.0)$ & $16.3(3.1)$ & $15.5(2.8)$ & $15.1(2.6)$ \\
\hline Joint space narrowing: x-ray evidence of knee severity & \multicolumn{4}{|c|}{ Percentage } \\
\hline OARSI grade 0 (normal) & 26.9 & 27.5 & 31.0 & 35.1 \\
\hline OARSI grade 1-2 (narrowed) & 52.2 & 51.5 & 46.6 & 48.2 \\
\hline OARSI grade 3 (severe) & 20.9 & 21.0 & 22.4 & 16.8 \\
\hline \multicolumn{5}{|l|}{ Multi-joint osteoarthritis } \\
\hline Bilateral knee OA & 68.4 & 66.0 & 60.9 & 53.3 \\
\hline Any back pain (30 days) & 66.5 & 56.7 & 56.3 & 59.6 \\
\hline Hand osteoarthritis & 15.8 & 17.6 & 18.1 & 22.5 \\
\hline Hip symptoms (12 months) & 30.9 & 24.4 & 23.9 & 21.2 \\
\hline Total hip replacement & 0.8 & 2.5 & 1.8 & 1.9 \\
\hline \multicolumn{5}{|l|}{ History } \\
\hline History of knee injury & 52.8 & 46.8 & 47.2 & 46.0 \\
\hline History of knee surgery & 27.6 & 29.0 & 31.9 & 26.9 \\
\hline
\end{tabular}

*WOMAC score ranges from 0 to 20, with 20 indicating worst pain. KOOS score ranges from 0 (extreme symptoms) to 100 (no symptoms). 
for sociodemographic and clinical characteristics. We used a multinomial logistic regression model because the outcome variable of interest was four levels: 1) use of CAM only; 2) use of conventional medications only; 3) use of both; and 4) use of neither. The models produced odds ratios (ORs) and corresponding 95\% confidence intervals (CIs). Multicollinearity among the variables of interest was assessed and ruled out by evaluating a correlation matrix before the modeling process and then by carefully evaluating the standard errors as new variables were introduced into the model. Odds ratios for the KOOS- QOL scale and chair stand test were calculated as one standard deviation change in each variable. To determine correlates of CAM use stratified by BMI levels, we created separate logistic regression models for each BMI level. The outcome variable in these models was use of CAM (yes/no).

\section{Results}

Table 1 shows sociodemographic measures by BMI level. Most participants with BMI $\geq 35 \mathrm{~kg} / \mathrm{m}^{2}$ were women $(69.0 \%)$ and were younger than participants with $\mathrm{BMI}<25 \mathrm{~kg} / \mathrm{m}^{2}$ (27.5\% over 65 years of age vs. $49.9 \%)$. Seventy-four percent

Table 3 CAM use among participants with radiographic-confirmed knee OA by BMI level $(\mathbf{N}=\mathbf{2 , 6 7 5 )}$

\begin{tabular}{|c|c|c|c|c|}
\hline \multirow[t]{2}{*}{ Category $^{a}$} & $\begin{array}{c}\mathrm{BMI} \geq 35 \mathrm{~kg} / \mathrm{m}^{2} \\
(\mathrm{n}=364)\end{array}$ & $\begin{array}{c}\text { BMI between } 30 \\
\text { and }<35 \mathrm{~kg} / \mathrm{m}^{2} \\
(\mathrm{n}=804)\end{array}$ & $\begin{array}{c}\text { BMI between } 25 \\
\text { and }<30 \mathrm{~kg} / \mathrm{m}^{2} \\
(\mathrm{n}=1,042)\end{array}$ & $\begin{array}{c}\mathrm{BMI}<25 \mathrm{~kg} / \mathrm{m}^{2} \\
(\mathrm{n}=465)\end{array}$ \\
\hline & \multicolumn{4}{|c|}{ Percentage } \\
\hline Alternative medical systems & 1.1 & 0.8 & 1.1 & 2.2 \\
\hline Acupuncture & 0.3 & 0.5 & 0.5 & 1.5 \\
\hline Acupressure & 0.3 & 0 & 0.3 & 0.4 \\
\hline Chelation therapy & 0 & 0 & 0 & 0 \\
\hline Folk medicine & 0 & 0 & 0 & 0 \\
\hline Homeopathy & 0.3 & 0 & 0.4 & 0.2 \\
\hline Ayurveda/biofeedback/energy healing/ hypnosis/naturopathy & 0.8 & 0.3 & 0.3 & 0.4 \\
\hline Mind-body interventions & 11.8 & 10.8 & 8.4 & 14.6 \\
\hline Yoga/Tai Chi/Chi Gong/Pilates & 3.9 & 4.5 & 5.3 & 10.3 \\
\hline Relaxation therapy, meditation, breathing & 3.6 & 4.6 & 2.5 & 3.9 \\
\hline Spiritual activities & 7.1 & 4.4 & 2.7 & 3.2 \\
\hline Manipulation and body-based methods & 5.5 & 5.7 & 4.9 & 5.0 \\
\hline Chiropractic & 4.7 & 4.6 & 4.1 & 3.9 \\
\hline Massage & 2.5 & 1.7 & 1.6 & 1.7 \\
\hline Energy therapies (Copper bracelets or magnets) & 5.8 & 3.1 & 3.2 & 3.4 \\
\hline Biologically based therapies: topical agent & 18.1 & 15.1 & 11.9 & 9.7 \\
\hline Rubs, lotions, liniments, creams or oils(tiger balm/horse liniment) & 17.6 & 14.8 & 11.7 & 9.7 \\
\hline Capsaicin & 1.9 & 1.7 & 1.6 & 1.3 \\
\hline Biologically based therapies: diet & 2.2 & 0.8 & 0.9 & 1.7 \\
\hline Biologically based therapies: supplements & 23.4 & 29.2 & 32.9 & 41.3 \\
\hline Herbs & 1.7 & 1.9 & 1.2 & 2.2 \\
\hline Vitamins/minerals (nearly every day) & 5.2 & 6.0 & 6.3 & 7.5 \\
\hline Glucosamine (nearly every day) & 19.8 & 24.5 & 28.8 & 36.6 \\
\hline Methylsulfonylmethane (MSM) & 3.6 & 6.0 & 6.0 & 6.5 \\
\hline S-adenosylmethionine (SAMe) & 0.0 & 0.3 & 0.7 & 0.9 \\
\hline Chondroitin (nearly every day) & 19.0 & 22.1 & 26.5 & 32.5 \\
\hline \multicolumn{5}{|l|}{ Distribution ${ }^{b}$ of CAM use: } \\
\hline One & 28.3 & 32.0 & 33.0 & 35.1 \\
\hline Two & 11.3 & 9.8 & 9.1 & 14.4 \\
\hline Three or more & 5.0 & 4.2 & 3.5 & 4.3 \\
\hline
\end{tabular}

${ }^{a}$ As defined by the National Center for Complementary and Alternative Medicine;

${ }^{\mathrm{b}}$ Number of CAM use was defined on basis of the broader categories. 
Table 4 Conventional medication use among participants with radiographic-confirmed knee $\mathrm{OA}$ by $\mathrm{BMI}$ level $(\mathrm{N}=2,675)$

\begin{tabular}{|c|c|c|c|c|}
\hline \multirow[t]{2}{*}{ Category } & $\begin{array}{c}\mathrm{BMI} \geq 35 \mathrm{~kg} / \mathrm{m}^{2} \\
(\mathrm{n}=364)\end{array}$ & $\begin{array}{c}\text { BMI between } 30 \\
\text { and }<35 \mathrm{~kg} / \mathrm{m}^{2} \\
(\mathrm{n}=804)\end{array}$ & $\begin{array}{c}\text { BMI between } 25 \\
\text { and }<30 \mathrm{~kg} / \mathrm{m}^{2} \\
(\mathrm{n}=1,042)\end{array}$ & $\begin{array}{c}\mathrm{BMI}<25 \mathrm{~kg} / \mathrm{m}^{2} \\
(\mathrm{n}=465)\end{array}$ \\
\hline & \multicolumn{4}{|c|}{ Percentage } \\
\hline Acetaminophen & 18.1 & 11.4 & 9.7 & 8.8 \\
\hline Any NSAIDs & 35.4 & 26.9 & 24.2 & 23.2 \\
\hline Over-the-counter NSAIDs & 27.8 & 21.4 & 19.7 & 18.1 \\
\hline Prescription NSAIDs & 12.4 & 7.8 & 6.2 & 6.5 \\
\hline COX-2 Inhibitors & 9.9 & 8.5 & 8.7 & 6.9 \\
\hline Acetaminophen or NSAIDs & 45.9 & 34.1 & 29.9 & 28.4 \\
\hline Doxycycline & 0.3 & 0.4 & 0.5 & 0.0 \\
\hline Narcotics & 5.8 & 3.5 & 1.4 & 2.2 \\
\hline Knee injections $^{a}$ & 4.7 & 4.5 & 3.4 & 2.6 \\
\hline Hyaluronic acid & 1.1 & 1.1 & 1.2 & 0.9 \\
\hline Steroids & 4.4 & 3.7 & 2.0 & 1.3 \\
\hline \multicolumn{5}{|c|}{ Distribution of conventional medications: ${ }^{b}$} \\
\hline One & 34.6 & 29.5 & 27.1 & 26.7 \\
\hline Two & 13.5 & 9.1 & 7.9 & 6.9 \\
\hline Three or more & 5.5 & 3.0 & 2.1 & 1.5 \\
\hline
\end{tabular}

${ }^{\mathrm{a}}$ The sum of percentages of hyaluronic acid and steroid injections may not be equal to the total percentage of knee injections because participants may use both hyaluronic acid and steroids, or use injections other than hyaluronic acid and steroids.

${ }^{b}$ Number of conventional medication used was based on the first seven items in this table.

of participants with $\mathrm{BMI}<25 \mathrm{~kg} / \mathrm{m}^{2}$ were married whereas $53.4 \%$ of those with $\mathrm{BMI} \geq 35 \mathrm{~kg} / \mathrm{m}^{2}$ were. Sixty-six percent of participants with BMI $<25 \mathrm{~kg} / \mathrm{m}^{2}$ were at least a college graduate whereas $41 \%$ of those with $\mathrm{BMI} \geq 35 \mathrm{~kg} / \mathrm{m}^{2}$ had.

Table 2 shows clinical measures by BMI level. The mean KOOS QOL score for participants with BMI < $25 \mathrm{~kg} / \mathrm{m}^{2}$ was 69.5 (standard deviation: 21.0 ) and it was 53.5 in participants with $\mathrm{BMI} \geq 35 \mathrm{~kg} / \mathrm{m}^{2}$ (standard deviation: 25.1). The mean WOMAC pain scores was 6.1 in participants with $\mathrm{BMI} \geq 35 \mathrm{~kg} / \mathrm{m}^{2}$ (standard deviation: 4.7 ) and 2.8 in participants with $\mathrm{BMI}<25 \mathrm{~kg} / \mathrm{m}^{2}$ (standard deviation: 3.3). Severe joint space narrowing was $20.9 \%$ in participants with $\mathrm{BMI} \geq 35 \mathrm{~kg} / \mathrm{m}^{2}$ and $16.8 \%$ in participants with $\mathrm{BMI}<25 \mathrm{~kg} / \mathrm{m}^{2}$.

Table 3 shows specific CAM therapies stratified by BMI level. Fifty percent of participants with $\mathrm{BMI}<$ $25 \mathrm{~kg} / \mathrm{m}^{2}$ and $39.6 \%$ of participants with BMI $\geq 35 \mathrm{~kg} / \mathrm{m}^{2}$

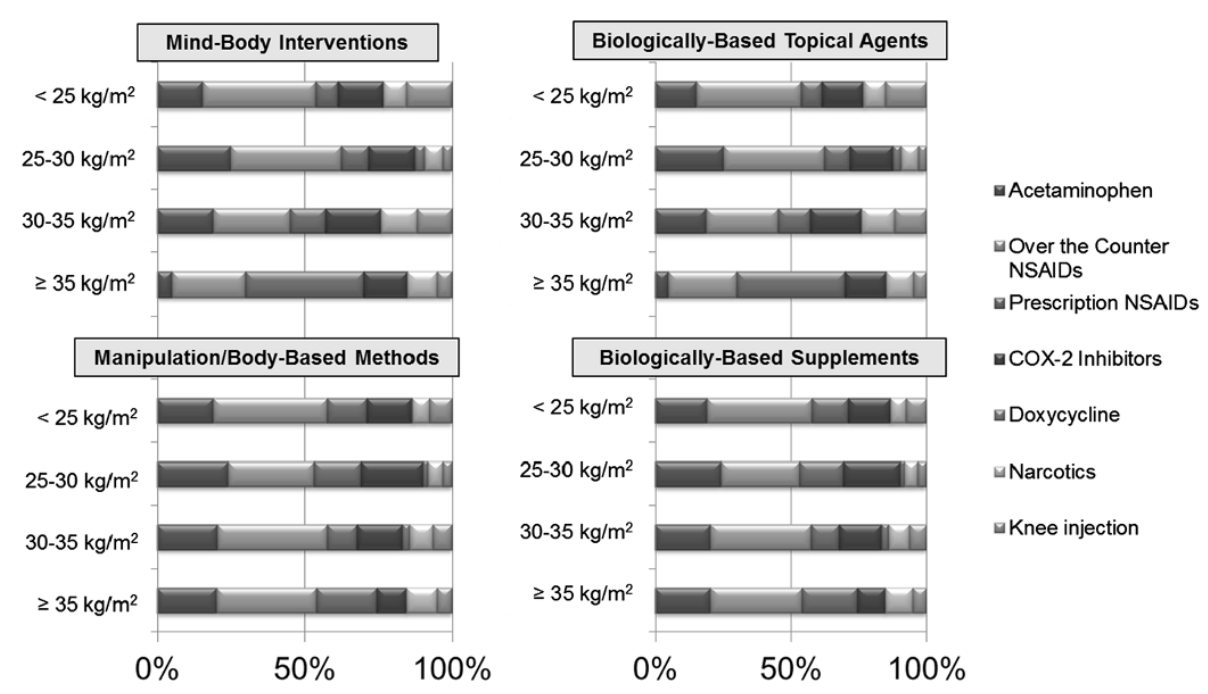

Figure 1 Distribution of concomitant conventional medication use among CAM users, stratified by BMI level. 
used one or two CAM therapies, either alone or with conventional medication. Although more participants with $\mathrm{BMI}<25 \mathrm{~kg} / \mathrm{m}^{2}$ used CAM overall relative to overweight and obese participants, differences by specific CAM type exist. Energy therapies were more common amongst overweight and obese participants $(5.8 \% \geq$ $35 \mathrm{~kg} / \mathrm{m}^{2}$ versus $3.4 \% \mathrm{BMI}<25 \mathrm{~kg} / \mathrm{m}^{2}$ ) as were topical therapies $\left(18.1 \% \geq 35 \mathrm{~kg} / \mathrm{m}^{2}\right.$ versus $\left.9.7 \% \mathrm{BMI}<25 \mathrm{~kg} / \mathrm{m}^{2}\right)$. Table 4, which shows specific conventional therapies by BMI level, indicates the reverse is true for conventional medications; $8.4 \%$ of participants with $\mathrm{BMI}<25 \mathrm{~kg} / \mathrm{m}^{2}$ and $19 \%$ of participants with $\mathrm{BMI} \geq 35 \mathrm{~kg} / \mathrm{m}^{2}$ reported at least two conventional medications. Doxycycline use was very low overall.

Figure 1 shows CAM use and types of concurrent conventional medication use by BMI level. The most commonly used concurrent conventional therapies amongst all BMI groups was acetaminophen and/or non-steroidal anti-inflammatory agents (NSAIDs) which were over-thecounter or prescription.

Table 5 shows the association between CAM and conventional treatment use and BMI level. Both participants with BMI between 30 and $35 \mathrm{~kg} / \mathrm{m}^{2}$ and participants with BMI between 25 and $30 \mathrm{~kg} / \mathrm{m}^{2}$ reported using CAM with conventional medications less often than participants with $\mathrm{BMI}<25 \mathrm{~kg} / \mathrm{m}^{2}$ (adjusted odds ratio (AOR): $0.38,95 \%$ CI: 0.20-0.73 for participants with BMI between 30 and $35 \mathrm{~kg} / \mathrm{m}^{2}$; AOR: 0.35, 95\% CI: 0.19-0.65 for participants with BMI between 25 and $30 \mathrm{~kg} / \mathrm{m}^{2}$ ).

Table 6 shows correlates of any CAM use by BMI level. Participants with BMI $\geq 35 \mathrm{~kg} / \mathrm{m}^{2}$ and over 65 years of age were more likely to use CAM than younger participants (AOR: 2.79, 95\% CI: 1.53-5.09). Black persons with BMI between 25 and $30 \mathrm{~kg} / \mathrm{m}^{2}$ were less likely to report CAM use compared to white persons (AOR: 0.36, 95\% CI: 0.23-0.58). Among persons with BMI of 25 to 30 and 30 to $35 \mathrm{~kg} / \mathrm{m}^{2}$, having a college degree or higher was associated with CAM use, relative to a high school education or less (AOR: 1.71 and 1.84, respectively).

\section{Discussion}

Persons with BMI levels of at least $25 \mathrm{~kg} / \mathrm{m}^{2}$ had greater prevalence of severe joint space narrowing, greater pain,

Table 5 Association between BMI level and treatment approaches among people with knee OA

\begin{tabular}{|c|c|c|c|}
\hline Treatment use & CAM only & Conventional medications only & Both \\
\hline & & Odds ratios & \\
\hline & & (95\% Confidence intervals) & \\
\hline \multicolumn{4}{|l|}{$\mathrm{BMI} \geq 35 \mathrm{~kg} / \mathrm{m}^{2}$ versus referent group $\mathrm{BMI}<25 \mathrm{~kg} / \mathrm{m}^{2}$} \\
\hline \multirow[t]{2}{*}{ Crude } & 0.48 & 2.51 & 1.38 \\
\hline & $(0.31-0.73)$ & $(1.55-4.07)$ & $(0.94-2.04)$ \\
\hline \multirow[t]{2}{*}{ Socio-demographic adjusted ${ }^{\dagger}$} & 0.50 & 1.69 & 1.16 \\
\hline & $(0.28-0.91)$ & $(0.81-3.53)$ & $(0.65-2.09)$ \\
\hline \multirow[t]{2}{*}{ Socio-demographic and clinical characteristic adjusted ${ }^{+\dagger}$} & 0.47 & 1.13 & 0.55 \\
\hline & $(0.24-0.92)$ & $(0.47-2.70)$ & $(0.27-1.12)$ \\
\hline \multicolumn{4}{|c|}{ BMI between 30 and $<35 \mathrm{~kg} / \mathrm{m}^{2}$ versus referent group $\mathrm{BMI}<25 \mathrm{~kg} / \mathrm{m}^{2}$} \\
\hline \multirow[t]{2}{*}{ Crude } & 0.70 & 1.71 & 0.94 \\
\hline & $(0.50-0.98)$ & $(1.09-2.68)$ & $(0.66-1.34)$ \\
\hline \multirow[t]{2}{*}{ Socio-demographic adjusted ${ }^{\dagger}$} & 0.71 & 1.29 & 0.71 \\
\hline & $(0.43-1.17)$ & $(0.65-2.57)$ & $(0.41-1.22)$ \\
\hline \multirow[t]{2}{*}{ Socio-demographic and clinical characteristic adjusted ${ }^{+\dagger}$} & 0.59 & 0.84 & 0.38 \\
\hline & $(0.34-1.04)$ & $(0.37-1.88)$ & $(0.20-0.73)$ \\
\hline \multicolumn{4}{|c|}{ BMI between 25 and $<30 \mathrm{~kg} / \mathrm{m}^{2}$ versus referent group $\mathrm{BMI}<25 \mathrm{~kg} / \mathrm{m}^{2}$} \\
\hline \multirow[t]{2}{*}{ Crude } & 0.68 & 1.29 & 0.77 \\
\hline & $(0.50-0.94)$ & $(0.83-2.01)$ & $(0.55-1.09)$ \\
\hline \multirow[t]{2}{*}{ Socio-demographic adjusted ${ }^{\dagger}$} & 0.49 & 0.78 & 0.52 \\
\hline & $(0.31-0.80)$ & $(0.39-1.55)$ & $(0.31-0.88)$ \\
\hline \multirow[t]{2}{*}{ Socio-demographic and clinical characteristic adjusted ${ }^{+\dagger}$} & 0.47 & 0.75 & 0.35 \\
\hline & $(0.28-0.79)$ & $(0.35-1.63)$ & $(0.19-0.65)$ \\
\hline
\end{tabular}

${ }^{\dagger}$ Adjusted for age, gender, race/ethnicity, marital status, education, employment status, income, health insurance, prescription drug insurance, and depression. ${ }^{++}$Also adjusted for physical and mental health component scores, KOOS quality of life, WOMAC pain scale, weight at 25 years of age, hip replacement, history of knee surgery, complaints of pain in multiple joints, OARSI severity scale, isometric strength/chair stands, and 20-meter walk. 
Table 6 Correlates of CAM use among participants with radiographic-confirmed knee OA by BMI level

\begin{tabular}{|c|c|c|c|c|}
\hline & $\begin{array}{c}\mathrm{BMI} \geq 35 \mathrm{~kg} / \mathrm{m}^{2} \\
(\mathrm{n}=364)\end{array}$ & $\begin{array}{c}\text { BMI between } 30 \\
\text { and }<35 \mathrm{~kg} / \mathrm{m}^{2} \\
(\mathrm{n}=804)\end{array}$ & $\begin{array}{c}\text { BMI between } 25 \\
\text { and }<30 \mathrm{~kg} / \mathrm{m}^{2} \\
(\mathrm{n}=1,042)\end{array}$ & $\begin{array}{c}\mathrm{BMI}<25 \mathrm{~kg} / \mathrm{m}^{2} \\
(\mathrm{n}=465)\end{array}$ \\
\hline & \multicolumn{4}{|c|}{ Odds ratios $(95 \% \text { Confidence intervals) })^{a}$} \\
\hline Age $\geq 65$ years & $2.79(1.53-5.09)$ & $1.29(0.89-1.86)$ & $1.01(0.73-1.39)$ & $1.22(0.72-2.06)$ \\
\hline Women & $1.85(1.08-3.15)$ & $1.56(1.11-2.17)$ & $1.66(1.25-2.21)$ & $3.27(2.03-5.27)$ \\
\hline \multicolumn{5}{|l|}{ Race/ethnicity } \\
\hline Black & $0.87(0.51-1.48)$ & $0.84(0.57-1.25)$ & $0.36(0.23-0.58)$ & $1.06(0.42-2.71)$ \\
\hline Latino & $1.04(0.13-8.13)$ & $1.73(0.24-12.34)$ & $0.98(0.33-2.97)$ & $1.53(0.30-7.68)$ \\
\hline Other & $0.20(0.02-2.14)$ & $1.69(0.57-5.00)$ & $1.48(0.54-4.07)$ & $2.35(0.63-8.81)$ \\
\hline Non-hispanic white & 1.0 & 1.0 & 1.0 & 1.0 \\
\hline \multicolumn{5}{|l|}{ Education } \\
\hline$\geq$ College graduate & $0.96(0.49-1.87)$ & $1.84(1.20-2.82)$ & $1.71(1.14-2.56)$ & $1.58(0.80-3.13)$ \\
\hline Some college & $1.00(0.52-1.91)$ & $1.54(0.97-2.43)$ & $1.43(0.91-2.24)$ & $1.37(0.63-2.96)$ \\
\hline High school or less & 1.0 & 1.0 & 1.0 & 1.0 \\
\hline Employment status & $2.21(1.26-3.88)$ & $1.08(0.75-1.55)$ & $0.83(0.61-1.13)$ & $1.66(1.01-2.73)$ \\
\hline Depression & $1.28(0.66-2.50)$ & $0.89(0.52-1.52)$ & $0.95(0.55-1.64)$ & $0.34(0.14-0.81)$ \\
\hline KOOS-QOL ${ }^{\mathrm{b}}$ & $0.70(0.53-0.91)$ & $0.55(0.45-0.66)$ & $0.66(0.57-0.78)$ & $0.62(0.48-0.80)$ \\
\hline Multi-joint osteoarthritis & $1.36(0.79-2.33)$ & $1.64(1.17-2.30)$ & $1.25(0.94-1.68)$ & $1.96(1.24-3.11)$ \\
\hline Isometric strength/chair stands (seconds) & $0.92(0.71-1.19)$ & $0.78(0.66-0.93)$ & $1.06(0.91-1.23)$ & $0.95(0.74-1.21)$ \\
\hline OARSI $^{\complement}$ Grade 3 (severe) & $1.87(0.92-3.79)$ & $1.28(0.79-2.06)$ & $1.60(1.07-2.39)$ & $2.49(1.26-4.91)$ \\
\hline Grade 1-2 (narrowed) & $1.27(0.73-2.22)$ & $1.08(0.74-1.56)$ & $1.15(0.84-1.58)$ & $1.17(0.73-1.86)$ \\
\hline Grade 0 (normal) & 1.0 & 1.0 & 1.0 & 1.0 \\
\hline
\end{tabular}

${ }^{a}$ Models stratified by obesity levels. ${ }^{b}$ Odds ratios are per one standard deviation change in KOOS-QOL scale and chair stand test. ${ }^{c} \mathrm{X}$-ray evidence of joint space narrowing.

and reduced quality of life relative to persons with $\mathrm{BMI}<25 \mathrm{~kg} / \mathrm{m}^{2}$. Despite a greater disease burden among persons with $B M I \geq 25 \mathrm{~kg} / \mathrm{m}^{2}$, we observed less CAM use and greater conventional medication use relative to those with $\mathrm{BMI}<25 \mathrm{~kg} / \mathrm{m}^{2}$. Our study was consistent with general population studies in that use of individual CAM modalities were less common in those with higher BMI levels, albeit differences were modest [13]. Chiropractic use did not differ substantially by levels of BMI, which was not consistent with studies showing less chiropractic use among obese persons [29]. Considering all individual CAM modalities, CAM use, either alone or in conjunction with conventional medications, was less common among persons with higher BMI levels. We acknowledge that the clinical relevance of some of the observed differences is unclear.

The correlates of CAM use differed by BMI level for some, but not all factors. Women were more likely to report use of CAM for knee OA than men and quality of life was inversely associated with CAM use. Age of at least 65 years was associated with CAM use only among those with $\mathrm{BMI} \geq 35 \mathrm{~kg} / \mathrm{m}^{2}$. Black participants tended to have lower odds of CAM use relative to white participants among those with BMI between 25 and $<30 \mathrm{~kg} / \mathrm{m}^{2}$. This association was not evident among other BMI levels. Our finding that black participants had reduced odds of use of CAM therapies than white participants was consistent with some previous studies [30]. The reasons for racial differences in CAM use are likely multifactorial, including different access to health care and socioeconomic positioning. In our study, black participants had less favorable socioeconomic positioning relative to white participants. Residual confounding from socioeconomic status may partially explain the inverse association. The reasons for inconsistent association between race and CAM use across BMI levels are unclear. Among persons with $\mathrm{BMI}<25 \mathrm{~kg} / \mathrm{m}^{2}$, depression was inversely associated with CAM use. We are unable to evaluate the extent to which these findings are consistent with the literature because, to our knowledge, no BMI level-specific correlates of CAM use have been published.

Given there is no cure for OA, the clinical implications of these findings must be considered. The use of CAM to slow disease progression is not supported by research, yet symptom relief among OA patients has been reported with glucosamine [11] and acupuncture [12]. Obesity is a modifiable risk factor for the development and treatment of knee pain [4]. Indeed, evidence from 
trials [5-7] suggests that intensive exercise and weight loss interventions result in improved pain and physical function measures. However, the beneficial effects of weight loss may be challenged by joint damage and chronic pain from $\mathrm{OA}$, which cause muscle atrophy, decreased mobility, poor balance, and eventual physical disability [4]. Some researchers have suggested that adoption of weight loss strategies may be hampered by pain, and that intensive treatment of pain resulting from knee OA may improve exercise capacity and quality of life [4].

The reasons why use of the treatment options is less among persons with higher BMI levels are likely multifactorial, and may include differences in patient preference, knowledge, and access to CAM. As the OAI did not collect such information, we were unable to explore the extent to which these factors explained observed differences. Reports show CAM users in general pursue generally healthy lifestyles [31], but use of CAM for weight loss remains relatively low [32]. The latter finding may suggest that persons with higher BMI levels may be reluctant to use CAM in general, rather than reluctant to use CAM specifically for OA symptom relief.

This study has several important limitations to consider. The data shown are cross-sectional. The temporal sequence of symptoms and treatment cannot be determined from this design. Data regarding symptoms and treatment are based on self-report and may have introduced bias. However, the information regarding conventional medications and CAM therapies are based on either a 30-day or 6-month recall. We believe this type of misclassification is likely minimal and non-differential with respect to BMI levels. Thus, if any distortions were introduced, they would have attenuated the observed associations. We are unable to comment on the extent to which patterns of CAM use by BMI levels indicate overuse of CAM by persons with lower BMI level or underuse of CAM by persons with higher BMI levels.

\section{Conclusion}

Our study suggests that despite increased burden of disease, overweight and obese patients with radiographicallyconfirmed knee OA are using CAM therapies less often than those with lower BMI levels, but use of conventional medications are more common in overweight and obese patients. Overweight and obese adults may be less likely to use effective CAM therapies relative to persons with $\mathrm{BMI}<25 \mathrm{mg} / \mathrm{k}^{2}$. Further research is needed to improve our understanding of the role of CAM in the treatment of knee OA among overweight and obese persons.

\section{Abbreviations}

BMI: Body mass index; CAM: Complementary and alternative medicine; OA: Osteoarthritis.

\section{Competing interests}

Dr. Eaton has consulted with Pfizer and Dr. Lapane with Janssen. None of the work conducted puts the authors in conflict with the current manuscript.

\section{Authors' contributions}

$\mathrm{KL}$ designed the analysis and wrote the first draft of the manuscript. SY conducted the analysis and interpreted the data. All authors have made substantial contributions to the conception and design and analysis and interpretation of the data. All authors have been involved in the revision of the manuscript for important intellectual content. All authors read and approved the final manuscript.

\section{Acknowledgements}

This study was funded by the National Institute of Arthritis and Musculoskeletal and Skin Disease (Project number 268201000020C-1-0-1 entitled TAS::75 0888::TAS to Charles Eaton). The Osteoarthritis Initiative (OAI) is a public-private partnership comprised of five contracts (N01-AR-2-2258; N01-AR-2-2259; N01-AR-2-2260; N01-AR-2-2261; N01-AR-2-2262) funded by the National Institutes of Health, a branch of the Department of Health and Human Services, and conducted by the OAI Study Investigators. Private funding partners include Pfizer, Inc.; Novartis Pharmaceuticals Corporation; Merck Research Laboratories; and GlaxoSmithKline. Private sector funding for the OAl is managed by the Foundation for the National Institutes of Health. This manuscript was prepared using an OAl public use data set and does not necessarily reflect the opinions or views of the OAl investigators, the $\mathrm{NIH}$ or the private funding partners. The funder had no role in this manuscript.

\section{Author details}

'Department of Quantitative Health Sciences, University of Massachusetts Medical School, Worcester, MA, USA. ${ }^{2}$ Department of Epidemiology and Community Health, Virginia Commonwealth University, Richmond, VA, USA. ${ }^{3}$ Department of Rheumatology Tufts Medical School, Boston, MA, USA. ${ }^{4}$ Center for Primary Care and Prevention, Memorial Hospital of Rhode Island, Pawtucket, RI, USA. ${ }^{5}$ Department of Family Medicine, Warren Alpert Medical School, Brown University, Providence, RI, USA.

Received: 27 June 2013 Accepted: 24 September 2013

Published: 28 September 2013

\section{References}

1. Reijman M, Pols HA, Bergink AP, Hazes JM, Belo JN, Lievense AM, BiermaZeinstra SM: Body mass index associated with onset and progression of osteoarthritis of the knee but not of the hip: the Rotterdam Study. Ann Rheum Dis 2007, 66:158-162.

2. Sharma L, Song J, Felson DT, Cahue S, Shamiyeh E, Dunlop DD: The role of knee alignment in disease progression and functional decline in knee osteoarthritis. JAMA 2001, 286:188-195.

3. Felson DT, Zhang Y, Anthony JM, Naimark A, Anderson JJ: Weight loss reduces the risk for symptomatic knee osteoarthritis in women. The Framingham Study. Ann Intern Med 1992, 116:535-539.

4. Felson DT, Naimark A, Anderson J, Kazis L, Castelli W, Meenan RF: The prevalence of knee osteoarthritis in the elderly. The Framingham Osteoarthritis Study. Arthritis Rheum 1987, 30:914-918.

5. Messier SP, Loeser RF, Miller GD, Morgan TM, Rejeski WJ, Sevick MA, Ettinger WH Jr, Pahor M, Williamson JD: Exercise and dietary weight loss in overweight and obese older adults with knee osteoarthritis: The arthritis, diet, and activity promotion trial. Arthritis Rheum 2004, 50:1501-1510.

6. Foy CG, Lewis CE, Hairston KG, Miller GD, Lang W, Jakicic JM, Rejeski WJ, Ribisl PM, Walkup MP, Wagenknecht LE: Intensive lifestyle intervention improves physical function among obese adults with knee pain: findings from the Look AHEAD trial. Obes 2011, 19:83-93.

7. Brosseau $L$, Wells GA, Tugwell $P$, Brosseau $L$, Wells GA, Tugwell $P$, Egan $M$, Dubouloz CJ, Casimiro L, Bugnariu N, Welch VA, De Angelis G, Francoeur L, Milne S, Loew L, McEwan J, Messier SP, Doucet E, Kenny GP, Prud'homme D, Lineker S, Bell M, Poitras S, Li JX, Finestone HM, Laferrière L, HainesWangda A, Russell-Doreleyers M, Lambert K, Marshall AD, et al. Ottawa panel evidence-based clinical practice guidelines for the management of osteoarthritis in adults who are obese or overweight. Phys Ther 2011, 91:843-861. 
8. Brady T, Kruger J, Helmick C, Callahan L, Boutaugh M: Intervention programs for arthritis and other rheumatic diseases. Health Educ Behav 2003, 30:44-63.

9. National Center for Complementary and Alternative Medicine: What is complementary and alternative medicine (CAM)?. http://nccam.nih.gov/ health/whatiscam.

10. Barnes P, Powell-Griner E: Complementary and alternative medicine Use among adults: United States, 2002. In Advance Data in Vital and Health Statistics volume 343. Hyattsville, MD: National Center for Health Statistics; 2004.

11. Towheed TE, Maxwell L, Anastassiades TP, Shea B, Houpt J, Robinson V, Hochberg MC, Wells G: Glucosamine therapy for treating osteoarthritis. Cochrane Database Syst Rev 2005, 2:CD002946.

12. Manheimer $E$, Cheng K, Linde K, Lao L, Yoo J, Wieland S, van der Windt DA, Berman BM, Bouter LM: Acupuncture for peripheral joint osteoarthritis. Cochrane Database Syst Rev 2010, 1:CD001977.

13. Bertisch SM, Wee CC, McCarthy EP: Use of complementary and alternative therapies by overweight and obese adults. Obes 2008, 16:1610-1615.

14. Nevitt MC, Felson DT, Lester G: The osteoarthritis initiative protocol for the cohort study. http://oai.epi-ucsforg/datarelease/docs/StudyDesignProtocol.pdf.

15. Altman RD, Hochberg M, Murphy WA, Wolfe F, Lequesne M: Atlas of individual radiographic features in osteoarthritis. Osteoarthritis Cartilage 1995, 3(Suppl A):3-70.

16. World Health Organization: Obesity: preventing and managing the global epidemic. Report of a WHO consultation on obesity. World Health Organ Tech Rep Ser 1998, 1:1-158.

17. Cheung CK, Wyman JF, Halcon LL: Use of complementary and alternative therapies in community-dwelling older adults. J Altern Complement Med 2007, 13:997-1006

18. Gray CM, Tan AW, Pronk NP, O'Connor PJ: Complementary and alternative medicine use among health plan members. A cross-sectional survey. Eff Clin Pract 2002, 5:17-22.

19. Katz P, Lee F: Racial/ethnic differences in the use of complementary and alternative medicine in patients with arthritis. J Clin Rheumato 2007, 13:3-11.

20. Graham RE, Ahn AC, Davis RB, O'Connor BB, Eisenberg DM, Phillips RS: Use of complementary and alternative medical therapies among racial and ethnic minority adults: results from the 2002 National Health Interview Survey. J Natl Med Assoc 2005, 97:535-545.

21. Ndao-Brumblay SK, Green CR: Predictors of complementary and alternative medicine use in chronic pain patients. Pain Med 2010, 11:16-24.

22. Ware J, Kosinski M, Keller SD: A 12-item short-form health survey: construction of scales and preliminary tests of reliability and validity. Med Care 1996, 34:220-233.

23. Radloff $L S$ : The CES-D scale: a self-report depression scale for research in the general population. Appl Psychol Meas 1977, 1:385-401.

24. Roos EM, Klssbo M, Lohmander LS: WOMAC osteoarthritis index. Reliability, validity, and responsiveness in patients with arthroscopically assessed osteoarthritis. Western Ontario and MacMaster Universities. Scand J Rheumatol 1999, 28:210-215.

25. Greidanus N, Peterson R, Masri B, Garbuz D: Quality of life outcomes in revision versus primary total knee arthroplasty. J Arthroplasty 2011, 26:615-620

26. Roos EM, Roos HP, Lohmander LS, Ekdahl C, Beynnon BD: Knee injury and osteoarthritis outcome score (KOOS)-development of a selfadministered outcome measure. J Orthop Sports Phys Ther 1998, 28:88-96.

27. Dunlop D, Song J, Semanik P, Sharma L, Chang R: Physical activity levels and functional performance in the osteoarthritis initiative: a graded relationship. Arthritis Rheum 2011, 63:127-136.

28. Studenski S, Perera S, Wallace D, Chandler JM, Duncan PW, Rooney E, Fox M, Guralnik JM: Physical performance measures in the clinical setting. J Am Geriatr Soc 2003, 51:314-322.

29. Ndetan HT, Bae S, Evans MW Jr, Rupert RL, Singh KP: Characterization of health status and modifiable risk behavior among United States adults using chiropractic care as compared with general medical care. J Manipulative Physiol Ther 2009, 32:414-422.

30. Mikuls T, Mudano A, Pulley L, Saag K: The association of race/ethnicity with the receipt of traditional and alternative arthritis-specific health care. Med Care 2003, 41:1233-1239.
31. Davis MA, West AN, Weeks WB, Sirovich BE: Health behaviors and utilization among users of complementary and alternative medicine for treatment versus health promotion. Health Serv Res 2011, 46:1402-1416.

32. Sharpe PA, Blanck HM, Williams JE, Ainsworth BE, Conway JM: Use of complementary and alternative medicine for weight control in the United States. J Altern Complement Med 2007, 13:217-222.

doi:10.1186/1472-6882-13-241

Cite this article as: Lapane et al.: CAM use among overweight and obese persons with radiographic knee osteoarthritis. BMC

Complementary and Alternative Medicine 2013 13:241.

\section{Submit your next manuscript to BioMed Central and take full advantage of:}

- Convenient online submission

- Thorough peer review

- No space constraints or color figure charges

- Immediate publication on acceptance

- Inclusion in PubMed, CAS, Scopus and Google Scholar

- Research which is freely available for redistribution

Submit your manuscript at www.biomedcentral.com/submit
C Biomed Central 